\title{
The Transfer of the Remittance Fee from the Migrant to the Household
}

\author{
Akira Shimada \\ Nagasaki University
}

\begin{abstract}
This paper discusses the problem of increasing remittances. It is often argued that the remittance fee needs to be lowered to increase remittances. We show that remittances become larger by increasing the receiving fee whereas they become larger by reducing the sending fee. We also show that, by transferring the sending fee from the migrant to the household, remittances become larger than those without the transfer. It is shown that for this purpose the home country's government can collect the sending fee from the household as taxes, and to pay it to the migrant as a subsidy.
\end{abstract}

-JEL Classification: D64, F22, F24

- Key Words: Migrant, Household, Transfer, Remittance Fee, Altruism

\section{Introduction}

In this paper, we discuss the problem of increasing the amount of remittances, assuming a simplified economy in which a representative migrant working in the host country sends part of his wages to a representative household in the home country as remittances. We are going to show that the home country can realize a larger amount of remittances by transferring the remittance fee from the migrant to the household.

Today, the amount of remittances is increasing very rapidly, and numerous studies have been conducted on remittances. Among them, the motives for, and the

\footnotetext{
*Corresponding address: Akira Shimada, Faculty of Economics, Nagasaki University, 4-2-1, Katafuchi, Nagasaki City, 850-8506, Japan. Tel : 8195820 6353, E-mail: shimada@nagasaki-u.ac.jp ๑2010-Center for International Economics, Sejong Institution, Sejong University, All Rights Reserved.
} 
use of, remittances have been most contentious. Debates on these issues are not likely to be conclusive. ${ }^{1}$

In spite of this, remittances have become one of the most important sources of external financing for many developing countries. According to Ratha (2005), remittance flows rank behind foreign direct investment (FDI) as a source of external funding for developing countries. Remittances contribute substantially to the development of the economy and the alleviation of poverty. They are used as capital for investment. They are also an important source of funds for low-income households. Many households often depend on them to cover day-to-day living expenses and to provide a cushion against emergencies. We can infer from these facts that remittances have positive effects on the home country of migrants. ${ }^{2}$

Accordingly, many developing countries are actually attempting to increase remittances, and international organizations such as the World Bank are also promoting remittances. ${ }^{3}$

There is widespread recognition that in order to increase remittances we should lower the remittance fee. According to Ratha (2005), the average cost of sending remittances is in the range of $9.5 \%$, and in some cases it exceeds $20 \% .{ }^{4}$ This is due to weakness in the financial sector. To increase remittances, Ratha (2005) argued that the financial sector should be strengthened. Specific policy recommendations

\footnotetext{
${ }^{1}$ Many researchers argue for various motives. In addition to altruism and self-interest, motives such as coinsurance between migrants and households, or repayment of a loan from their families, are also considered to explain the reasons for sending remittances. Different motives are, of course, not mutually exclusive. See Lucas and Stark (1985), Rapoport and Docquier (2006), and Ruiz and Vargas-Silva (2009) for the motives for sending remittances. There are two major arguments regarding the use of remittances. One group of studies, e.g., Durand et al. (1996), Taylor (1999), Woodruff and Zenteno (2001), argues that a significant part of remittances is used for investment and development purposes. Another group of studies, e.g., Massey and Parrado (1994), Koc and Onan (2004), Semyonov and Gorodzeisky (2008), argues that most of remittances are used for consumption and non-development purposes.

${ }^{2}$ However, remittances may also have some unpleasant consequences. For example, remittances may impair the household's incentive to work (Amuedo-Dorantes and Pozo, 2006). Negative outcomes also arise from asymmetric information about the household's effort between migrants and households (Chami et al., 2005), or from the presence of moral hazard (Naiditch and Vranceanu, 2009).

${ }^{3}$ This does not mean that increasing the amount of remittances is not without problems. There are people who abuse remittances. Remittances may be larger because of increases in money laundering and terrorism financing. In addition, increases in informal remittances will prevent the deepening of the home country's financial system.

${ }^{4}$ According to an estimate introduced by Ratha (2005), the fee to send US $\$ 200$ to Cuba is US $\$ 25.6$, the fee to Columbia is US\$18.8, the fee to Jamaica is US\$19.2, the fee to Dominican Republic is US\$18.2, the fee to Haiti is US\$20.4, the fee to Guatemala is US\$15.2, the fee to Nicaragua is US\$17.6, the fee to Mexico is US\$11.6, the fee to EL Salvador is US\$15.0. Of course, various factors influence the fee, and there are cases of relatively inexpensive fees.
} 
for increasing remittances were provided by Ratha and Riedberg (2005). De Luna Martínez (2005) argued that both remittance-sending and remittance-receiving countries must make efforts to reduce the remittance fee, and that co-ordination for this purpose between the authorities of these countries is necessary. Brown (2006) and Carling (2008) also advocated fee reduction. Freund and Spatafora (2008) empirically confirmed the negative effects of the remittance cost on the amount of remittances. Moreover, faced with the declining estimates on remittance flows to developing countries in 2009, Ratha stated in the press release of the World Bank (2009) that reducing remittance fees and developing innovative tools to leverage remittances for financial inclusion and capital market access are necessary as a part of our response to the financial crisis.

Remittance fees are usually classified into two kinds; fees that migrants must pay for sending remittances and the fees that households must pay for receiving remittances. ${ }^{5}$ These fees are likely to have different effects on remittances, depending on the relationship between migrants and households.

Many of previous studies were implicitly referring to the sending fee. However, except for De Luna Martínez (2005), they have not clearly specified which fee should be lowered. Moreover, even if lowering the fee is an appropriate policy, we cannot easily implement it. This is not only because the home country's government cannot directly control the fee that is usually set by the private financial institutions, in other words, normally the fee is given for the government, but also because, even if the government can manipulate, changing the fee will affect the interests of the agents involved in sending and receiving remittances.

Therefore, in this paper we distinguish between the sending fee and the receiving fee, and we examine how these fees affect remittances, giving the ratios of remittances spent on investment and spent on consumption by the household exogenously. Based on this inquiry, we try to find a way to increase the amount of remittances under the constraints that we cannot manipulate the fees and that we must not cause the conflicts of the interests among agents.

We find that remittances decrease with the sending fee but increase with the receiving fee. We also find that the home country can increase the amount of remittances by transferring the sending fee from the migrant to the household. Such a transfer does not have to change the fees and does not affect the interests of

${ }^{5}$ In general the fee is paid by the sender. However, the fee is also paid by the receiver when, for example, banks charge the fee for depositing remittances in the receiver's account, for the use of an ATM to withdraw funds, or for the payment of money orders (De Luna Martìnez, 2005, p.15). 
agents involved. Therefore, the home country's government can realize such a transfer by collecting the sending fee from the household as taxes, and paying it to the migrant as a subsidy.

The remainder of this paper proceeds as follows. In Section II, we model an economy consisting of a representative migrant and a representative household. In Section III, we examine the effects of the remittance fees on the amount of remittances. In Section IV, by introducing the transfer, we try to maximize remittances, without manipulating the fee and without affecting the interests of agents. In Section $\mathrm{V}$, we present concluding remarks.

\section{The Model}

This section models an economy in which migrants work in the host country and send remittances, and households remain in the home country and receive remittances.

The representative migrant earns income by $\bar{Y}_{M}^{*}$ in the host country's currency. Hereafter, the uppercase letters with (without) an asterisk are expressed in the host (home) country's currency. $\bar{Y}_{M}^{*}$ is given exogenously and does not change throughout the analysis. The representative migrant sends remittances to his household. We assume that migrants are altruistic towards households, and that at the same time they are seeking their self-interest. Accordingly, remittances are made for both altruistic and self-interest motives. The amount of remittances $R^{*}\left(<\bar{Y}_{M}^{*}\right)$ is determined by the representative migrant to maximize his utility.

The representative household earns income by $\bar{Y}_{H}$ before receiving remittances, and spends part of the remitted money on its present consumption, and the rest on investment for the migrant's future consumption, as specified by the representative migrant. ${ }^{6}$ In particular, the ratio $1-k$, where $k$ is a constant and $0<k<1$, of remittances after paying the receiving fee, is spent on the household's present consumption and the ratio $k$ is spent on investment for the migrant's future consumption.

Households care about the well-being of migrants, i.e. they are also altruistic towards migrants. Accordingly, as assumed in the first chapter of Stark (1995) and

\footnotetext{
${ }^{6}$ This is a simplifying assumption. In general how the household spends remittances should be determined endogenously, possibly by comparing the utility derived from consuming remittances and the utility derived from investing remittances. In addition, it is likely that the migrant does not have perfect information on how remittances are actually spent by the household.
} 
pp.1143-1145 of Rapoport and Docquier (2006), migrants and households are mutually altruistic.

Remittances are made through formal channels, and migrants and households have to pay a fee to send and receive remittances. We denote the sending fee and the receiving fee by $\bar{F}_{M}^{*}$ and $\bar{F}_{H}$, respectively. We give the sending fee and the receiving fee exogenously, independently of the amount of the remittances. We also give the exchange rate, which is defined as the home country's currency price of the host country's currency, exogenously. ${ }^{7}$ In particular, we assume that it is equal to one. Since the exchange rate is assumed to be unique, there is no exchange spread.

From these assumptions, the income of the representative migrant after sending remittances can be represented as $\bar{Y}_{M}^{*}-R^{*}-\bar{F}_{M}^{*}$. The migrant spends all of this on the present consumption in the host country. Remittances after paying the receiving fee are divided into investment for the migrant's future consumption $k\left(R^{*}-\bar{F}_{H}\right)$ and the household's present consumption $(1-k)\left(R^{*}-\bar{F}_{H}\right)$. The household spends its earned income as well as part of remittances $\bar{Y}_{H}+(1-k)\left(R^{*}-\bar{F}_{H}\right)$ on its present consumption.

We represent the direct utility of the representative migrant $V_{M}$ as follows:

$$
V_{M}\left(\bar{Y}_{M}^{*}-R^{*}-\bar{F}_{M}^{*}, k\left(R^{*}-\bar{F}_{H}\right)\right), V_{M 1}, V_{M 2}>0, V_{M 11}, V_{M 22}<0, V_{M 12}>0 .
$$

Present consumption and future consumption both increase the direct utility, marginal utilities are decreasing, and present consumption and future consumption are complements, in the sense that $V_{M 12}>0$.

On the other hand, the direct utility of the representative household depends only on its present consumption.

$$
V_{H}\left(\bar{Y}_{H}+(1-k)\left(R^{*}-\bar{F}_{H}\right)\right), V_{H}^{\prime}>0, V_{H}^{\prime \prime}<0 \text {. }
$$

\footnotetext{
${ }^{7}$ This is a simplifying assumption. In general, remittances affect the exchange rate, and the exchange rate affects remittances. Solimano (2003) mentioned the so-called 'Dutch disease' effect. There is a tendency for the real exchange rate to appreciate in countries receiving substantial remittances. This has negative impacts on non-traditional exports and the development of the tradable goods sector. Similarly, Amuedo-Dorantes and Pozo (2004) found that remittances have the potential to appreciate the real exchange rate in the receiving economies, thereby reducing the competitiveness of their exported goods in the international economy. On the other hand, Faini (1994) showed that the real exchange rate affects the long-run desired level of workers' remittances. Yang (2008) found that, during the 1997 Asian financial crisis, the appreciation of the migrant's currency against the Philippine peso led to increases in Philippine households' remittance receipts.
} 
Present consumption increases the direct utility, and the marginal utility is decreasing.

Since, as assumed already, migrants and households are mutually altruistic, the utility of the representative migrant $U_{M}$ depends not only on his own direct utility, but also on the utility of the representative household. Similarly, the household utility $U_{H}$ depends not only on its own direct utility, but also on the utility of the representative migrant. Accordingly, the utility of the representative migrant and the utility of the representative household can be expressed as follows:

$$
\begin{aligned}
& U_{M}=\left(1-\beta_{M}\right) V_{M}+\beta_{M} U_{H}, \\
& U_{H}=\left(1-\beta_{H}\right) V_{H}+\beta_{H} U_{M},
\end{aligned}
$$

where $\beta_{M}, 0<\beta_{M}<1$, is the weight that the representative migrant places on the utility of the representative household, and $\beta_{H}, 0<\beta_{H}<1$, is the weight that the representative household places on the utility of the representative migrant.

We solve Equations (1m) and (1h) for $V_{M}$ and $V_{H}$.

$$
\begin{aligned}
& U_{M}=\left(1-\alpha_{M}\right) V_{M}+\alpha_{M} V_{H}, \\
& U_{H}=\left(1-\alpha_{H}\right) V_{H}+\alpha_{H} V_{M},
\end{aligned}
$$

where $\alpha_{M}=\frac{\beta_{M}\left(1-\beta_{H}\right)}{1-\beta_{M} \beta_{H}}, \alpha_{H}=\frac{\beta_{H}\left(1-\beta_{M}\right)}{1-\beta_{M} \beta_{H}}$ and $0<\alpha_{M}<1,0<\alpha_{H}<1$.

\section{The Effects of Remittance Fees on Remittances}

This section examines how the amount of remittances is related to the sending fee and the receiving fee. As mentioned, since the government cannot control these fees directly, this section is not intended to drive the effects of the government's policy, i.e. the effects of the government's manipulation of the fees on the amount of remittances, but to clarify the effects of the fees on remittances.

As assumed already, the representative migrant determines the amount of remittances in such a manner as to maximize his utility. Making $d U_{M} / d R^{*}$ equal to zero, we obtain, 


$$
-\left(1-\alpha_{M}\right) V_{M 1}+\left(1-\alpha_{M}\right) V_{M 2} k+\alpha_{M} V_{H}^{\prime}(1-k)=0 .
$$

The second-order condition that $d^{2} U_{M} / d R^{* 2}$ is negative is satisfied.

We totally differentiate Equation (3) to derive the effects of the sending fee and the receiving fee on remittances.

$$
\begin{gathered}
\frac{d R^{*}}{d \bar{F}_{M}^{*}}=-\frac{A}{A+B} \\
\frac{d R^{*}}{d \bar{F}_{H}}=\frac{B}{A+B} .
\end{gathered}
$$

where

$$
\begin{gathered}
A \equiv\left(1-\alpha_{M}\right) V_{M 11}-\left(1-\alpha_{M}\right) V_{M 21} k \\
B \equiv-\left(1-\alpha_{M}\right) V_{M 12} k+\left(1-\alpha_{M}\right) V_{M 22} k^{2}+\alpha_{M}(1-k)^{2} V_{H}^{\prime \prime} .
\end{gathered}
$$

Since $A, B<0$, Equation (4) suggests that remittances before paying the fees, i.e. "total remittances" are decreasing with the sending fee. Of course, remittances after paying the sending fee are also decreasing. Consequently, the sending fee should be reduced if we are to increase the amount of remittances. This result is in line with the arguments made by many researchers.

Reducing the sending fee is beneficial to both the migrant and the household. This is because the income of the representative migrant after sending remittances, investment made by the representative household for the migrant's future consumption, and the income of the representative household spent on its present consumption become larger as the sending fee decreases. ${ }^{8}$

On the other hand, reducing the sending fee is likely to have negative impacts on the sending agents in the host country.

We can infer from these considerations that reducing the sending fee has the conflicting impacts on the interests of agents involved.

According to Equation (5), total remittances increase with the receiving fee. This

$\overline{{ }^{8} d\left(\bar{Y}_{M}^{*}-R^{*}-\bar{F}_{M}^{*}\right) / d \bar{F}_{M}^{*}}=-B /(A+B)<0$. 
can be explained intuitively as follows: With a larger receiving fee, the household's present consumption and investment for the migrant's future consumption would be much smaller if the migrant did not increase remittances before paying the receiving fee, i.e. "total remittances". ${ }^{9}$ The arguments made by many researchers do not apply to the case of the receiving fee because we have to increase the receiving fee if we are to make the amount of remittances larger.

Increasing the receiving fee may be beneficial to the paying agents in the home country. However, it has negative impacts on the migrant and the household. This is because remittances after paying the receiving fee become smaller with increases in the receiving fee, which leads to the lower amounts of investment made by the household for the migrant's future consumption and the present consumption by the household. ${ }^{10}$ Moreover, the migrant's income after sending remittances decreases with the receiving fee. ${ }^{11}$ These make the migrant's utility and the household's utility lower.

Therefore, similar to the case of the sending fee, increasing the receiving fee also has the conflicting impacts on the interests of agents involved.

Summarizing the results derived in this section, the sending fee and the receiving fee are related to the amount of remittances in a different manner. Moreover, with changes in the sending fee and the receiving fee, the conflicts of the interests among agents arise.

\section{Maximizing Remittances through the Transfer}

This section tries to find a way to maximize remittances without manipulating the fees and without causing the conflicts of the interests among agents. For this purpose, we assume that the migrant may bear part or all of the receiving fee, as well as the sending fee, or that the household may bear part or all of the sending fee, as well as the receiving fee. In other words, the fees can be transferred between the migrant and the household. This section considers the government's policy under the constraints, i.e. manipulation of taxes and a subsidy that maximizes

\footnotetext{
${ }^{9}$ However, as will be mentioned shortly, with increases in the receiving fee, remittances after paying the receiving fee, i.e. "net remittances" become smaller. As a result, the household's present consumption and investment for the migrant's future consumption decrease with increases in the receiving fee.

${ }^{10} d\left(R^{*}-\bar{F}_{H}\right) / d \bar{F}_{H}=-A /(A+B)<0$.

${ }^{11} d\left(\bar{Y}_{M}^{*}-R^{*}-\bar{F}_{M}^{*}\right) / d \bar{F}_{H}=\{-B /(A+B)\}<0$.
} 
remittances through the transfer, referring to the effects of the fees on remittances under no transfer derived in the previous section.

We assume that the representative migrant and the representative household bear the ratio $\theta$ and the ratio $1-\theta$ of the total fee $\bar{F}_{M}{ }^{*}+\bar{F}_{H}\left(\equiv \bar{F}^{*}\right)$, respectively, where $\theta$ is $0 \leq \theta \leq 1$.

Under this assumption, the utility of the representative migrant $\tilde{U}_{M}$ under the transfer and the utility of the representative household $\tilde{U}_{H}$ under the transfer are expressed as follows:

$$
\begin{aligned}
& \tilde{U}_{M}=\left(1-\alpha_{M}\right) \tilde{V}_{M}+\alpha_{M} \tilde{V}_{H} . \\
& \tilde{U}_{H}=\left(1-\alpha_{H}\right) \tilde{V}_{H}+\alpha_{H} \tilde{V}_{M} .
\end{aligned}
$$

where

$$
\begin{gathered}
\tilde{V}_{M}=\tilde{V}_{M}\left(\bar{Y}_{M}^{*}-R^{*}-\theta \bar{F}^{*}, k\left(R^{*}-(1-\theta) \bar{F}^{*}\right)\right), \tilde{V}_{M i}=V_{M i}, \tilde{V}_{M i j}=V_{M i j}, i, j=1,2, \\
\tilde{V}_{H}=\tilde{V}_{H}\left(\bar{Y}_{H}+(1-k)\left(R^{*}-(1-\theta) \bar{F}^{*}\right)\right), \tilde{V}_{H}^{\prime}=V_{H}^{\prime}, \tilde{V}_{H}^{\prime \prime}=V_{H}^{\prime \prime} .
\end{gathered}
$$

The representative migrant tries to maximize his utility by manipulating the amount of remittances. Making $d \tilde{U}_{M} / d R^{*}$ equal to zero, we obtain,

$$
-\left(1-\alpha_{M}\right) \tilde{V}_{M 1}+\left(1-\alpha_{M}\right) \tilde{V}_{M 2} k+\alpha_{M} \tilde{V}_{H}^{\prime}(1-k)=0 .
$$

The second-order condition that $d^{2} \tilde{U}_{M} / d R^{* 2}$ is negative is satisfied.

Totally differentiating Equation (7), the effects of $\theta$ on remittances are derived as follows:

$$
\frac{d R^{*}}{d \theta}=-\bar{F}^{*}
$$

According to Equation (8), the amount of remittances decreases with $\theta$, and is thereby maximized when $\theta$ is equal to zero, i.e. when the migrant does not pay the sending fee and the household pays both the sending and the receiving fees.

This result is related to the effects of the fees on remittances under no transfer. In particular, we showed that remittances decrease with the sending fee (Equation 4) and increase with the receiving fee (Equation 5). By making $\theta$ equal to 0 , the fee to 
be paid by the migrant becomes the smallest and the fee to be paid by the household becomes the largest. As a result, remittances are maximized when $\theta$ is equal to 0 .

If we can transfer the sending fee from the migrant to the household, the migrant will not have to pay the sending fee at all and the household will pay both the fees. Moreover, by doing so, remittances become larger than those without any transfer. When there is no transfer, the representative migrant pays the sending fee, which is equal to $\bar{F}_{M}^{*} /\left(\bar{F}_{M}^{*}+\bar{F}_{H}\right)$ of the total fee. Accordingly, $\theta$ is positive under no transfer. However, if we allow for the transfer, as mentioned, remittances become larger by making $\theta$ equal to zero.

Then, how can we realize such a transfer? For this purpose, the home country's government may be able to collect the sending fee from the household as taxes, and paying it to the migrant as a subsidy.

However, if there were anyone who would become worse off by the transfer, the government could not realize such a transfer that utilizes taxes and a subsidy. Under the transfer, even if the total fee is shared in the different ratios, the income of the representative migrant after sending remittances $\bar{Y}_{M_{*}}^{*} R^{*}-\theta \bar{F}^{*}$ does not change, and remittances after paying the fee $R^{*}-(1-\theta) \bar{F}^{*}$ also do not change. Accordingly, the migrant's utility and the household's utility do not depend on the way the total fee is shared by these agents. ${ }^{12}$ Moreover, the sending agents are able to collect the same amount of the fee as under no transfer, and the paying agents are also able to collect the same amount of the fee as under no transfer. As a result, no one becomes worse off by the transfer through taxes and a subsidy.

Therefore, we can conclude that the home country's government can realize a transfer of the sending fee from the migrant to the household by collecting the

\footnotetext{
${ }^{12}$ In order to derive Equation (7), we maximized $\tilde{U}_{M}$ with respect to $R^{*}$, by giving the value of $\theta$ arbitrary. Accordingly, if the value of $\theta$ is given differently, $R^{*}$ that maximizes $U_{M}$ (let us denote such $R^{*}$ by $\left.\left[R^{*}\right]^{*}\right)$ differs. In other words, the value of $\left[R^{*}\right]^{*}$ depends $\theta$ As Equation (8) shows, $\left[R^{*}\right]^{*}$ is decreasing with $\theta$. In particular, if $0 \leq \theta_{1}<\theta_{2} \leq 1$, then $\left.\left[R^{*}\right]^{*}\right|_{\theta=\theta_{1}}>\left.\left[R^{*}\right]^{*}\right|_{\theta=\theta_{2}}$. The effects of $\theta$ on $\tilde{U}_{M}, \tilde{U}_{H}$ will be understood if we consider the effects of $\theta$ on $\bar{Y}_{M}^{*}-R^{*}-\theta \bar{F}^{*}$ and $R^{*}-(1-\theta) \bar{F}^{*}$. As mentioned, both of them remain unchanged. This suggests that when $R^{*}$ is determined to maximize $\tilde{U}_{M}$, the migrant's utility and the household' utility do not differ under the different values of $\theta$, i.e.
}

$$
\begin{aligned}
& \tilde{U}_{M}\left(\left.\left[R^{*}\right]^{*}\right|_{\theta=\theta_{1}}\right)=\tilde{U}_{M}\left(\left.\left[R^{*}\right]^{*}\right|_{\theta=\theta_{2}}\right), \\
& \tilde{U}_{H}\left(\left.\left[R^{*}\right]^{*}\right|_{\theta=\theta_{1}}\right)=\tilde{U}_{H}\left(\left.\left[R^{*}\right]^{*}\right|_{\theta=\theta_{2}}\right) .
\end{aligned}
$$

Therefore, manipulation of $\theta$ to maximize $R^{*}$, that maximizes the migrant utility, has no effect on the welfare of the migrant and the household. 
sending fee from the household as taxes, and paying it to the migrant as a subsidy, and by doing so, we can attain the larger amount of remittances.

Summarizing the results derived in this section, we considered the government's policy to maximize remittances under the constraints that we cannot manipulate the fees and that we must not harm the interests of agents involved. We showed that the transfer utilizing taxes and a subsidy is possible and that remittances are larger than under no transfer.

\section{Concluding Remarks}

We showed that, by transferring the sending fee from the migrant to the household, the home country can receive a larger amount of remittances. Since such a transfer does not affect the interests of agents involved, it is feasible for the home country's government to impose taxes on the household to collect the sending fee, and to pay it to the migrant as a subsidy to implement the transfer.

Many researchers argue that the remittance fee should be lowered. However, they are not distinguishing between the sending fee and the receiving fee explicitly. According to our investigation, to increase remittances, the sending fee and the receiving fee have to be changed to opposite directions. However, in actual economies, the home country's government cannot control these fees perfectly. Moreover, as our model predicts, changing the fees really has conflicting impacts on the interests of agents. These considerations suggest that transferring the sending fee from the migrant to the household is a practical and effective way to increase the amount of remittances.

\section{Acknowledgements}

I would like to extend my sincere gratitude to anonymous referees for giving me the very constructive comments. This paper was presented at the 8th International Conference of the Japan Economic Policy Association held in Tokyo, November 2009 and at the All China Economics (ACE) International Conference held in Hong Kong, December 2009. I am grateful to the participants for their valuable comments. Needless to say, any remaining errors are my responsibility.

Received 15 February 2010, Revised 6 July 2010, Accepted 20 July 2010 


\section{References}

Amuedo-Dorantes, C. and Pozo, S. (2004), "Workers' Remittances and the Real Exchange Rate: A Paradox of Gifts", World Development, Vol. 32, pp. 1407-1417. Amuedo-Dorantes, C. and Pozo, S. (2006), "Migration, Remittances, and Male and Female Employment Patterns", American Economic Review, Vol. 96, pp. 222-226.

Brown, S. S. (2006), "Can Remittances Spur Development? A Critical Survey", International Studies Review, Vol. 8, pp. 55-75.

Carling, J. (2008), "The Determinants of Migrant Remittances", Oxford Review of Economic Policy, Vol. 24, pp. 581-598.

Chami, R., Fullenkamp,C., and Jahjah, S. (2005), "Are Immigrant Remittance Flows a Source of Capital for Development?", IMF Staff Papers, Vol. 52, pp. 55-81.

De Luna Martínez, J. (2005), "Workers' Remittances to Developing Countries: A Survey with Central Banks on Selected Public Policy Issues", World Bank Policy Research Working Paper 3638.

Durand, J., Kandel,W., Parrado, E. A., and Massey, D. S. (1996), "International Migration and Development in Mexican Communities", Demography, Vol. 33, pp. 249-264.

Faini, R. (1994), "Workers Remittances and the Real Exchange Rate: A Quantitative Framework", Journal of Population Economics, Vol. 7, pp. 235-245.

Freund, C. and Spatafora, N. (2008), "Remittances, Transaction Costs, and Informality", Journal of Development Economics, Vol. 86, pp. 356-366.

Koc, I. and Onan, I. (2004), 'International Migrants' Remittances and Welfare Status of the Left-Behind Families in Turkey", International Migration Review, Vol. 38, pp. 78-112.

Lucas, R. E. B. and Stark, O. (1985), "Motivations to Remit: Evidence from Botswana", Journal of Political Economy, Vol. 93, pp. 901-918.

Massey, D. S. and Parrado, E. (1994), "Migradollars: The Remittances and Savings of Mexican Migrants to the USA", Population Research and Policy Review, Vol. 13, pp. 330 .

Naiditch, C. and Vranceanu, R. (2009), "Migrant Wages, Remittances and Recipient Labour Supply in a Moral Hazard Model”, Economic Systems, Vol. 33, pp. 60-82.

Rapoport, H. and Docquier, F. (2006), “The Economics of Migrants' Remittances, in Handbook of the Economics of Giving, Altruism and Reciprocity: Applications, (Ed.) Kolm, S.-C. and Ythier, J. M., Elsevier Science B. V., Amsterdam, pp.1135-1198.

Ratha, D. (2005), "Workers' Remittances: an Important and Stable Source of External Development Finance", in Remittances: Development Impact and Future Prospects (Ed.) Maimbo, S. M. and Ratha, D., World Bank, Washington DC, pp. 19-51.

Ratha, D. and Riedberg, J. (2005), “On Reducing Remittance Costs”, Unpublished Paper, World Bank.

Ruiz, I. and Vargas-Silva, C. (2009), "To Send, or Not to Send: That is the Question; A Review of the Literature on workers' Remittances", Journal of Business Strategies, Vol. 26, pp. 65-90. 
Semyonov, M. and Gorodzeisky, A. (2008), "Labor Migration, Remittances and Economic Well-being of Households in the Philippines", Population Research and Policy Review, Vol. 27, pp. 619-637.

Solimano, A. (2003), "Remittances by Emigrants: Issues and Evidence, World Institute for Development Economics Research, United Nations University, Discussion Paper No.2003/89.

Stark, O. (1995), Altruism and Beyond, Cambridge, Cambridge University Press.

Taylor, E. J. (1999), "The New Economics of Labour Migration and the Role of Remittances in the Migration Process, International Migration, Vol. 37, pp. 63-88.

Woodruff, C. M. and Zenteno, R. (2001), "Remittances and Microenterprises in Mexico", SCCIE Working Paper No. 01-25 (Santa Cruz Center for International Economics). Available via the Internet: http://papers.ssrn.com/sol3/papers.cfm?abstract_id $=282019$.

World Bank. (2009), Remittance Flows to Developing Countries to Decline by $7.3 \%$ in 2009, Predicts World Bank: Updated Estimates Released at July 13-14 International Diaspora and Development Conference, Press Release No: 2010/024/DEC. Available via the Internet: http://web.worldbank.org/WBSITE//EXTERNAL/NEWS/0, content MDK:22243070 pagePK:34370 piPK:34424 PKtheSitePK: 4607,00.html.

Yang, D. (2008), "International Migration, Remittances and Household Investment: Evidence from Philippine Migrants' Exchange Rate Shocks”, Economic Journal, Vol. 118, pp. 591-630. 